\title{
Video Article \\ Use of a Hanging Weight System for Coronary Artery Occlusion in Mice
}

\author{
Tobias Eckle ${ }^{1}$, Michael Koeppen ${ }^{1}$, Holger Eltzschig ${ }^{1}$ \\ ${ }^{1}$ Department of Anesthesiology, University of Colorado Denver
}

Correspondence to: Tobias Eckle at tobias.eckle@ucdenver.edu

URL: https://www.jove.com/video/2526

DOI: doi:10.3791/2526

Keywords: Medicine, Issue 50, Cardioprotection, preconditioning, targeted gene deletion, murine, model, ischemia, reperfusion, heart

Date Published: 4/19/2011

Citation: Eckle, T., Koeppen, M., Eltzschig, H. Use of a Hanging Weight System for Coronary Artery Occlusion in Mice. J. Vis. Exp. (50), e2526, doi:10.3791/2526 (2011).

\section{Abstract}

Murine studies of acute injury are an area of intense investigation, as knockout mice for different genes are becoming increasingly available ${ }^{1-38}$ Cardioprotection by ischemic preconditioning (IP) remains an area of intense investigation. To further elucidate its molecular basis, the use of knockout mouse studies is particularly important ${ }^{7,14,30,39}$. Despite the fact that previous studies have already successfully performed cardiac ischemia and reperfusion in mice, this model is technically very challenging. Particularly, visual identification of the coronary artery, placement of the suture around the vessel and coronary occlusion by tying off the vessel with a supported knot is technically difficult. In addition, re-opening the knot for intermittent reperfusion of the coronary artery during IP without causing surgical trauma adds additional challenge. Moreover, if the knot is not tied down strong enough, inadvertent reperfusion due to imperfect occlusion of the coronary may affect the results. In fact, this can easily occur due to the movement of the beating heart.

Based on potential problems associated with using a knotted coronary occlusion system, we adopted a previously published model of chronic cardiomyopathy based on a hanging weight system for intermittent coronary artery occlusion during IP ${ }^{39}$. In fact, coronary artery occlusion can thus be achieved without having to occlude the coronary by a knot. Moreover, reperfusion of the vessel can be easily achieved by supporting the hanging weights which are in a remote localization from cardiac tissues.

We tested this system systematically, including variation of ischemia and reperfusion times, preconditioning regiments, body temperature and genetic backgrounds ${ }^{39}$. In addition to infarct staining, we tested cardiac troponin I (cTnl) as a marker of myocardial infarction in this model. In fact, plasma levels of cTnl correlated with infarct sizes $(R 2=0.8)$. Finally, we could show in several studies that this technique yields highly reproducible infarct sizes during murine IP and myocardial infarction, $6,30,40,41$. Therefore, this technique may be helpful for researchers who pursue molecular mechanisms involved in cardioprotection by IP using a genetic approach in mice with targeted gene deletion. Further studies on cardiac IP using transgenic mice may consider this technique.

\section{Video Link}

The video component of this article can be found at https://www.jove.com/video/2526/

\section{Protocol}

\section{General remarks:}

All operations should be performed under an upright dissecting microscope (Olympus, SZX10 with Z-Axis Crank Post with STU2 StandBoom Stand) and using a surgical coagulator. Ventilation is critical for the procedure and therefore a certain amount of time should be spent on choosing the ventilator and optimizing the ventilation technique. Temperature, blood pressure and anesthesia should be stable throughout.

\section{Anesthesia, Intubation and Monitoring}

1. Use C57BL/6 mice that are at least 10 weeks old. Induce anesthesia using sodium pentobarbital at a dose $70 \mathrm{mg} / \mathrm{kg}$ body weight i.p. Maintain anesthesia with approximately $10 \mathrm{mg} / \mathrm{kg} / \mathrm{h}$ sodium pentobarbital. Be cautious with overdosing since this might significantly lower the blood pressure. Re-dosing of pentobarbital - even after hrs- can lead to severe increases in plasma levels. Based on strong evidence regarding isoflurane as cardioprotective compound we recommend the use of the 'inert' and well established pentobarbital in a model for myocardial ischemia $^{46-56}$.

2. Place mice on a temperature-controlled heated table (RT, Effenberg, Munich, Germany) with a rectal thermometer probe attached to thermal feedback controller to maintain body temperature at $37^{\circ} \mathrm{C}$.

3. After anesthesia induction secure mice in a supine position, with the upper and lower extremities attached to the table using a tape and a suture fastened to the ankles. Do the same for the head by using the teeth. A sufficient restraining is important for a successful intubation and well controlled surgery. Prior to surgery, cover the mouse with mineral oil to reduce the risk of mouse hair allergy.

4. Expose the trachea surgically and perform a tracheal intubation using bluntpolyethylene cannulae (Insyte 22g, Beckton Dickinson, USA). You will have to blunt the needle to be able to use it as a stylet. 
5. Pull the tongue out using a pair of forceps and then push gently in a 15-degree angle towards the body. Even after exposure of the trachea and using a microscope, this might require some training. Be aware that a small damage of the trachea might lead to the inability to ventilate the animal throughout the suture. Thus, if you encounter airway problems check the trachea for small holes.

6. Confirm correct tube placement by direct visualization of the cannula within the previously exposed trachea above the carina.

7. Connect the tube to a ventilator. We recommend a pressure controlled ventilation technique by using a Servo $900 \mathrm{C}$ from Siemens (DRE Veterinary, USA). Animals will then be ventilated using peak inspiratory pressure of $10 \mathrm{mbar}$, frequency of $110 \mathrm{breaths} / \mathrm{min}$ and a positive end-expiratory pressure of 3-5 mbar with a $\mathrm{FiO}_{2}=0.4$. Settings might need some adjustments that can be achieved most easily by checking the lungs during open thorax surgery. Make sure that the lungs are not collapsed or overextended. Despite of the fact that the Servo $900 \mathrm{C}$ is built as ventilator for humans, its use in a pressure controlled ventilator setting works excellent for the ventilation of mice.

8. Perform Blood gas analysis to confirm normal gas exchange (partial pressure of oxygen, $\mathrm{paO}_{2}$ of $115 \pm 15 \mathrm{mmHg}$ and partial pressure of carbon dioxide, $\mathrm{paCO}_{2}$ of $38 \pm 6 \mathrm{mmHg}$ ) after 4 to 6 hours of ventilation time using the i-STAT System (Abbott, USA).

9. Monitor heart rate with an ECG (e.g. Hewlett Packard, Böblingen, Germany). Make sure that the heart rate does not drop below 450. If the mouse develops bradicardia check the temperature and the anesthetic dose/concentration. Xylacin/ Ketamin anesthesia induces a heart heart of $250 / \mathrm{min}$ and is therefore not recommended.

10. Apply a proper fluid replacement. An infusion with normal saline $0.1 \mathrm{ml} /$ hour via an arterial or venous catheter should be performed prior to the onset of ischemia. Also, a saline bolus of $500 \mu \mathrm{l}$ could be given i.p. prior to surgery. Thoractomy can induce a drop in blood pressure and may require additional saline boli. After ischemia, an infusion rate up to $1 \mathrm{ml} / \mathrm{hour}$ might be necessary to maintain a mean arterial blood pressure above $60 \mathrm{mmHg}$ and to guarantee a sufficient reperfusion critical for infarct staining using TTC.

11. Place a carotid artery (PE10, Tip O.D. (mm/"), Tapered>.024 mm/.011") for continuous recording of blood pressure. The carotid artery will be exposed via blunt dissection of the paratracheal muscles. Following further exposure and careful avoidance of any tissue trauma (particular of the vagal nerve), a catheter is inserted into the vessel using two sutures and a small clamp. Attach the arm to the body before you start dissecting the artery. This will expose a longer piece of the artery. Knot the very end of the proximal part of the carotid artery. Attach a larger clamp to the end of the suture to obtain tension. Place another suture around the artery and dissect the artery to the very distal end. Here, place a small clamp. Use micro scissors to cut a small diagonal opening into the artery. Hold the opening with a fine forceps (Dumont, WPI) and advance the proper sized catheter with your hands/forceps. Make a knot with your second suture and secure the artery. Loosen the clamp and advance the catheter further. Secure the catheter with several knots and tape.

\section{Technique of Coronary Artery Occlusion}

1. Dissect the skin and expose the left thorax wall using a blunt dissection technique.

2. Cut the muscles pectorals majors and minors to expose the thorax wall with a cautery. By pulling the pectoralis major, the lung drops, thereby a forceps from the electrosurgical unit can be inserted, and, 1-3 mm above the lung, a horizontal line crossing the rips should be coagulated.

3. By using a blunted scissor, cut the thorax wall. Modified safety pins, where the catch plate is removed and the blunt end is bent, are then used to keep the thorax open.

4. To facilitate the final placement of the suture, coagulate and cut the thorax wall along the diaphragm towards the lower left side of the thorax.

5. Expose the heart by dissecting the pericardium. To avoid diaphragmatic movements remove and cut the phrenic nerve.

6. Use a small wet cotton stick with a forceps and turn the heart towards the right side. Identify the left coronary artery (LCA) and make sure that the lungs are not too inflated. Optimize the opening of the thorax to have a secure hold of the heart when placing the suture. If the blood pressure is too low the identification might be complicated. Additional boli of saline might improve identification of the LCA. The LCA is a bright red vessel crossing the heart horizontally (in contrast to the returning veins). Sometimes, the LCA is seen best without a microscope. Do not use too much light. This can lead to sever reflections making visualization impossible.

7. Once the LCA is visually identified, place an 8.0 nylon suture (Prolene, Ethicon, Notiefies, USA) around the LCA. For the purpose of intermittent LCA occlusion, we adopted a chronic model of cardiomyopathy ${ }^{42}$ using a hanging weight system.

8. Thread the suture through a small piece of plastic tube (PE-10 tubing) with blunt edges and attach two small weights (1g, e.g. use Eppendorf tubes filled with water) to each end. With the weights freely hanging over a rod, the LCA should immediately be occluded. In addition, when the weight is relieved, LCA occlusion is terminated at once. Successful LCA occlusion should be confirmed by an immediate color change of the vessel from light red to dark violet, change of color of the myocardium supplied by the vessel (from bright red to white) and the presence of ST-elevations in the ECG. During reperfusion, the changes of color instantly disappear. Keep the heart wet with a $37^{\circ} \mathrm{C}$, saline soaked, piece of absorbent cotton throughout (see also Figure 1).

9. Chose your ischemia time according your primary interest. In fact, for studies of cardioprotective effects of IP, it would be ideal to use an ischemia time associated with an in infarct sizes of approximately 30 to $40 \%$ of the AAR. Thus, it would be possible to demonstrate changes in both directions, e.g. smaller infarct sizes with cardiac IP or larger infarct sizes with an experimental therapeutic or a specific gene deletion. In addition, mice with an infarct size of less than $50 \%$ usually survive the experiment, whereas infarct sizes of 60 to $80 \%$ are often not survived and the animals die before the reperfusion time is complete. Using our model 10 minute of myocardial ischemia followed by 2 hours of reperfusion result in an infarct size of $3.5 \pm 1.3 \%$ of the AAR. In contrast, an ischemia time of 60 minutes results in a mean infarct size of $42 \pm 5.2 \%$ of the AAR $(p<0.01)^{39}$. Thus, we consider a 60 minutes of ischemia as ideal to study changes in both directions. Nevertheless, you might have to adjust the ischemia time in gene targeted mice with a sever phenotype.

10. Chose the right reperfusion time. The reperfusion time is critically important for TTC staining. The colorless dye is reduced to a brick-redcolored precipitate by dehydrogenases in the presence of the co-enzyme NADH. Dying cells lose their ability to retain NADH and, therefore, are delineated as pale areas within the red stained viable myocardium. Infarct size delineation by TTC requires that NADH has been washed out completely from the necrotic area. However, if reperfusion is not long enough, infarct size delineation by TTC staining may result in an underestimation of the actual infarct size ${ }^{43}$. In our hands, after an ischemia time of $60 \mathrm{~min}$, the infarct size measurement increased from $11.5 \pm 4.5 \%$ after 30 minutes to $42.2 \pm 5.1 \%$ after 120 minutes. No further increase in infarct size could be detected with longer reperfusion times (240 minutes) ${ }^{39}$. Thus, we recommend a 2 hour reperfusion period which seems also reasonable in the context of cardiac enzyme determination. If you consider ischemia preconditioning, we recommend 4 cycles of IP ( 5 min ischemia, 5 min reperfusion), followed by an ischemia time of $60 \mathrm{~min}$ and a reperfusion time of 2 hours. Under these conditions, IP was associated with a 3.2-fold reduction of infarct size from $42.2 \pm 5.1 \%$ to $13.3 \pm 3.3 \%$ of the $\mathrm{AAR}^{39}$. However, due to the hanging weight system, different preconditioning regiments could easily be applied. 


\section{Determination of the Area At Risk (AAR) and Myocardial Infarct Size}

After induction of a myocardial infarct (with or without IP), the area is perfused by the LCA (area at risk, AAR) and the size of the infarct itself will be determined using a staining technique. Subsequently, infarct will then be calculated as percentage of myocardial infarction compared to the AAR. To do this, a previously described double staining technique with Evan's blue and triphenyltetrazolium chloride (TTC) is used ${ }^{44}$.

1. Determine the AAR by retrograde injection of $1 \%$ Evan's blue dye into the aorta while the LCA is occluded. Alternatively, if a carotis catheter is in place, use this route for Evans blue injection. Evans blue will stain all myocardial tissue blue, except the AAR. It is critical for this step to avoid air bubbles within the catheter, as they would be injected into the coronary circulation and prevent Evan's blue staining. Prior to the Evans blue staining you might want to collect blood for cardiac enzyme measurements. In addition, removal of blood by injecting $5 \mathrm{ml}$ of saline via an aortic or carotis catheter is recommended.

2. Excise the heart and wash in ice cold $0.9 \%$ saline

3. Embed into $2 \%$ agarose. Do not use hot agarose since this will prevent successful staining

4. After 30 minutes at $+4^{\circ} \mathrm{C}$ (or 15 minutes $-20^{\circ} \mathrm{C}$ ), cut the heart into slices of $1 \mathrm{~mm}$ using a heart matrix or microtome. If you place the heart into the freezer avoid dry freezing which will lead to non stained hearts.

5. Incubate the slices with $1 \%$ TTC at $37^{\circ} \mathrm{C}$ for 10 min using a $15 \mathrm{ml}$ blue cap in a water bath. This will allow the infarcted area to be demarcated as a white area, while viable tissue stains red.

6. Fixate the stained slices with $10 \%$ fomaldehyde over night. By doing so, the infarcted area is better contrasted improving quality of pictures

7. Determine the area at risk (AAR) and the infarct size via planimetry using the NIH software Image $1.0^{45}$.

8. Calculate the percent of infarcted myocardium from the area at risk.

\section{Cardiac Enzyme Measurement}

Due to limitations associated with TTC staining we recommend as additional readout for myocardial infarct severity the determination of cardiac troponin I (cTnl) levels in the serum of mice. The blood will be obtained from the portal vein and serum cTnl levels are then determined with a quantitative rapid cTnl assay(Life Diagnostics, Inc., West Chester, PA, USA).

\section{Representative Results:}

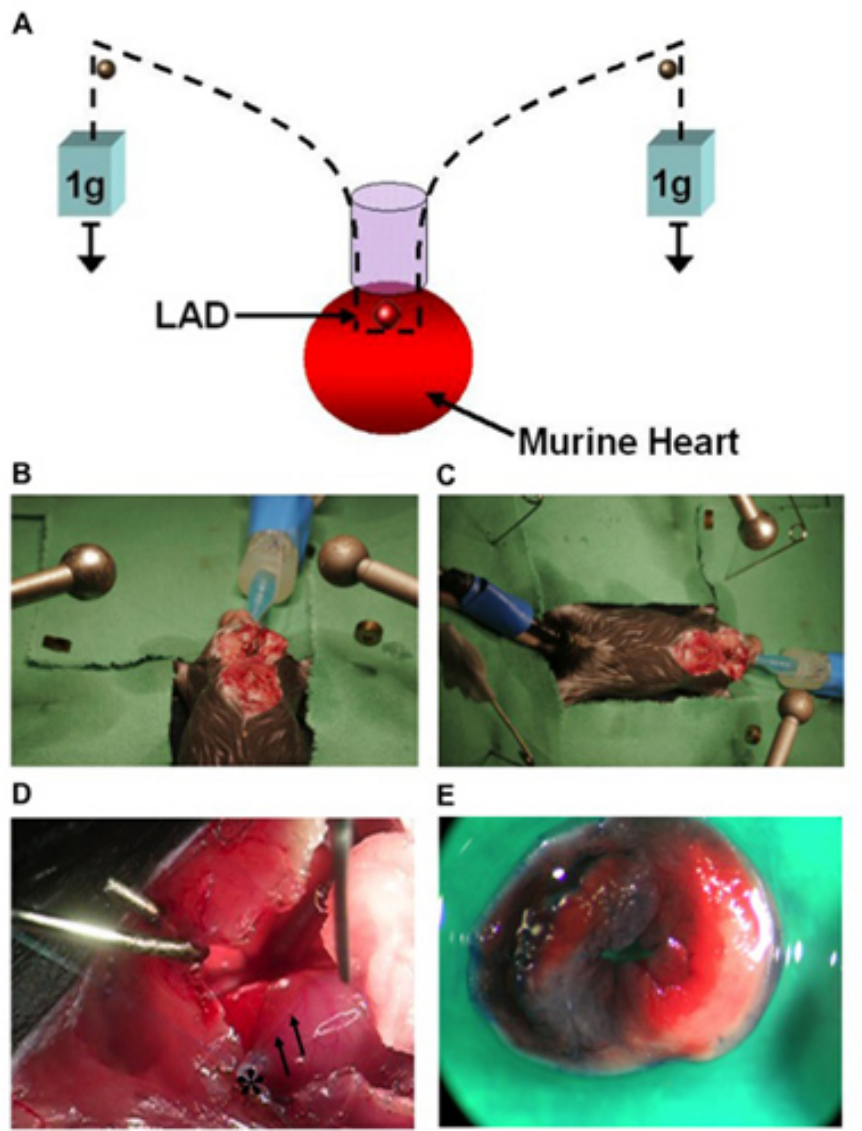

Figure 1. (A) Model of cardiac IP using a hanging-weight system of coronary occlusion. This technique does not require a knot for coronary occlusion. (B, C) Surgical setup. (D) Image of a murine heart with the left coronary artery (LCA, arrows) after occlusion. Visual identification of the LCA is necessary for ligation and ischemic preconditioning in mice. An 8.0 nylon suture is placed around the LCA 1-2 mm beneath the left auricle. The suture is threaded through a small plastic tube $\left(^{*}\right)$. The end of each suture is attached to a small weight $(1 \mathrm{~g})$ and the suture is placed 
over rods on both sides. (E) Determination of the AAR after LCA occlusion and retrograde injection of Evan's blue dye into the aorta. The AAR remains unstained while the rest of the myocardium is blue. After incubation of AAR tissue with TTC, the infarcted area stained white, while viable tissue stained red.

\section{Discussion}

The present study describes a novel technique of performing IP in an intact murine model using a hanging-weight system and thus avoiding coronary artery occlusion by a knot. In fact, this study demonstrates highly reproducible infarct sizes and cardiac protection by IP, thus minimizing the variability associated with knot-based coronary occlusion models. Investigators who consider studying cardioprotection by IP in mice may benefit from this model.

\section{Disclosures}

No conflicts of interest declared.

\section{Acknowledgements}

The present studies are supported by National Heart, Lung, and Blood Institute Grant R01-HL0921, R01-DK083385 and R01-HL098294 to H. K. Eltzschig, the 1K08HL102267-01 to T. Eckle, and Foundation for Anesthesia Education and Research Grants to T. Eckle and H. K. Eltzschig, and American Heart Association Grant to T. Eckle and H. K. Eltzschig and a Deutsche Forschungsgemeinschaft (DFG) research fellowship to M. Koeppen. We thank Shelley Eltzschig for the art work.

\section{References}

1. Eckle, T., Faigle, M., Grenz, A., Laucher, S., Thompson, L.F., \& Eltzschig, H.K. A2B adenosine receptor dampens hypoxia-induced vascular leak. Blood $111: 2024-2035$ (2008).

2. Eckle, T., Fullbier, L., Grenz, A. \& Eltzschig, H.K. Usefulness of pressure-controlled ventilation at high inspiratory pressures to induce acute lung injury in mice. Am J Physiol Lung Cell Mol Physiol 295 : L718-724 (2008).

3. Eckle, T., Fullbier, L., Wehrmann, M., Khoury, J., Mittelbronn, M., Ibla, J., Rosenberger, P., \& Eltzschig, H.K. Identification of ectonucleotidases CD39 and CD73 in innate protection during acute lung injury. J Immunol $178: 8127-8137$ (2007).

4. Eckle, T., Grenz, A., S., Laucher, \& Eltzschig, H.K. A2B adenosine receptor signaling attenuates acute lung injury by enhancing alveolar fluid clearance in mice. J Clin Invest $118: 3301-3315$ (2008).

5. Eckle, T., Koeppen, M., \& Eltzschig, H.K. Role of extracellular adenosine in acute lung injury. Physiology (Bethesda) 24 : $298-306$ (2009).

6. Eckle, T., Kohler, D., Lehmann, R., El Kasmi, K., \& Eltzschig, H.K. Hypoxia-inducible factor-1 is central to cardioprotection: a new paradigm for ischemic preconditioning. Circulation $118: 166-175$ (2008).

7. Eckle, T., Kohler, D., Lehmann, R., El Kasmi, K.C., \& Eltzschig, H.K. Hypoxia-Inducible Factor-1 Is Central to Cardioprotection: A New Paradigm for Ischemic Preconditioning. Circulation 118 : 166-175 (2008).

8. Eckle, T., Krahn, T., Grenz, A., Kohler, D., Mittelbronn, M., Ledent, C., Jacobson, M.A., Osswald, H., Thompson, L.F., Unertl, K., \& Eltzschig, H.K. Cardioprotection by ecto-5'-nucleotidase (CD73) and A2B adenosine receptors. Circulation $115: 1581-1590$ (2007).

9. Eltzschig, H.K. Adenosine: an old drug newly discovered. Anesthesiology 111 : 904-915 (2009).

10. Eltzschig, H.K., Abdulla, P., Hoffman, E., Hamilton, K.E., Daniels, D., Schonfeld, C., Loffler, M., Reyes, G., Duszenko, M., Karhausen, J., Robinson, A., Westerman, K.A., Coe, I.R., \& Colgan, S.P. HIF-1-dependent repression of equilibrative nucleoside transporter (ENT) in hypoxia. J. Exp. Med. 202 : 1493-1505 (2005).

11. Eltzschig, H.K., Eckle, T., Mager, A., Kuper, N., Karcher, C., Weissmuller, T., Boengler, K., Schulz, R., Robson, S.C., \& S.P. Colgan. ATP release from activated neutrophils occurs via connexin 43 and modulates adenosine-dependent endothelial cell function. Circ Res 99 : 1100-1108 (2006).

12. Eltzschig, H.K., Faigle, M., Knapp, S., Karhausen, J., Ibla, J., Rosenberger, P., Odegard, K.C., Laussen, P.C., Thompson, L.F., \& S.P. Colgan. Endothelial catabolism of extracellular adenosine during hypoxia: the role of surface adenosine deaminase and CD26. Blood 108: 1602-1610 (2006).

13. Eltzschig, H.K., Ibla, J.C., Furuta, G.T., Leonard, M.O., Jacobson, K.A., Enjyoji, K., Robson, S.C., \& S.P. Colgan. Coordinated adenine nucleotide phosphohydrolysis and nucleoside signaling in posthypoxic endothelium: role of ectonucleotidases and adenosine A2B receptors. J Exp Med 198 : 783-796 (2003).

14. Eltzschig, H.K., Kohler, D., Eckle, T., Kong, T., Robson, S.C., \& S.P. Colgan. Central role of Sp1-regulated CD39 in hypoxia/ischemia protection. Blood $113: 224-232$ (2009).

15. Eltzschig, H.K., Macmanus, C.F., \& S.P. Colgan. Neutrophils as Sources of Extracellular Nucleotides: Functional Consequences at the Vascular Interface. Trends Cardiovasc Med 18 : 103-107 (2008).

16. Eltzschig, H.K., J. Rivera-Nieves, \& S.P. Colgan. Targeting the A2B adenosine receptor during gastrointestinal ischemia and inflammation. Expert Opin Ther Targets $13: 1267-1277$ (2009).

17. Eltzschig, H.K., Thompson, L.F., Karhausen, J., Cotta, R.J., Ibla, J.C., Robson, S.C., \& S.P. Colgan. Endogenous adenosine produced during hypoxia attenuates neutrophil accumulation: coordination by extracellular nucleotide metabolism.Blood $104: 3986-3992$ (2004).

18. Eltzschig, H.K., Weissmuller, T., Mager, A., \& T. Eckle. Nucleotide metabolism and cell-cell interactions. Methods Mol Biol 341 : $73-87$ (2006).

19. Frick, J.S., MacManus, C.F., Scully, M., Glover, L.E., Eltzschig, H.K., \& S.P. Colgan. Contribution of adenosine A2B receptors to inflammatory parameters of experimental colitis. J Immunol 182 : 4957-4964 (2009).

20. Grenz, A., Osswald, H., Eckle, T., Yang, D., Zhang, H., Tran, Z.V., Klingel, K., Ravid, K., \& H.K. Eltzschig.The Reno-Vascular A2B Adenosine Receptor Protects the Kidney from Ischemia. PLoS Medicine 5 : e137 (2008). 
21. Grenz, A., Zhang, H., Eckle, T., Mittelbronn, M., Wehrmann, M., Kohle, C., Kloor, D., Thompson, L.F., Osswald, H., \& Eltzschig, H.K. Protective role of ecto-5'-nucleotidase (CD73) in renal ischemia. J Am Soc Nephrol 18 : 833-845 (2007).

22. Grenz, A., Zhang, H., Hermes, M., Eckle, T., Klingel, K., Huang, D.Y., Muller, C.E., Robson, S.C., Osswald, H., \& Eltzschig, H.K. Contribution of E-NTPDase1 (CD39) to renal protection from ischemia-reperfusion injury. FASEB J21 : 2863-2873 (2007).

23. Grenz, A., Zhang, H., Weingart, J., S. von Wietersheim, Eckle, T., Schnermann, J.B., Kohle, C., Kloor, D., Gleiter, C.H., Vallon, V., Eltzschig, H.K., \& H. Osswald. Lack of effect of extracellular adenosine generation and signalling on renal erythropoietin secretion during hypoxia. Am J Physiol Renal Physiol 00243.02007 (2007).

24. Hart, M.L., Gorzolla, I.C., Schittenhelm, J., Robson, S.C., \& Eltzschig, H.K. SP1-dependent induction of CD39 facilitates hepatic ischemic preconditioning. J Immunol 184 : 4017-4024 (2010).

25. Hart, M.L., Henn, M., Kohler, D., Kloor, D., Mittelbronn, M., Gorzolla, I.C., Stahl, G.L., \& Eltzschig, H.K. Role of extracellular nucleotide phosphohydrolysis in intestinal ischemia-reperfusion injury. FASEB J22 : 2784-2797 (2008).

26. Hart, M.L., Jacobi, B., Schittenhelm, J., Henn, M., \& Eltzschig, H.K. Cutting Edge: A2B Adenosine receptor signaling provides potent protection during intestinal ischemia/reperfusion injury. J Immunol 182 : 3965-3968 (2009).

27. Hart, M.L., Kohler, D., Eckle, T., Kloor, D., Stahl, G.L., \& Eltzschig, H.K. Direct treatment of mouse or human blood with soluble 5'nucleotidase inhibits platelet aggregation. Arterioscler Thromb Vasc Biol 28 : 1477-1483 (2008).

28. Hart, M.L., Much, C., Gorzolla, I.C., Schittenhelm, J., Kloor, D., Stahl, G.L., \& Eltzschig, H.K. Extracellular adenosine production by ecto-5'nucleotidase protects during murine hepatic ischemic preconditioning. Gastroenterology 135 : 1739-1750 e1733 (2008).

29. Koeppen, M., Eckle, T., \& Eltzschig, H.K. Selective deletion of the A1 adenosine receptor abolishes heart-rate slowing effects of intravascular adenosine in vivo. PLoS One 4 : e6784 (2009).

30. Kohler, D., Eckle, T., Faigle, M., Grenz, A., Mittelbronn, M., Laucher, S., Hart, M.L., Robson, S.C., Muller, C.E., \& Eltzschig, H.K. CD39/ ectonucleoside triphosphate diphosphohydrolase 1 provides myocardial protection during cardiac ischemia/reperfusion injury. Circulation $116:$ 1784-1794 (2007).

31. Kong, T., Westerman, K.A., Faigle, M., Eltzschig, H.K., \& S.P. Colgan. HIF-dependent induction of adenosine A2B receptor in hypoxia. Faseb $\mathrm{J} 20: 2242-2250(2006)$.

32. Loffler, M., J.C. Morote-Garcia, Eltzschig, S.A., Coe, I.R., \& Eltzschig, H.K. Physiological roles of vascular nucleoside transporters. Arterioscler Thromb Vasc Biol 27 : 1004-1013 (2007).

33. Morote-Garcia, J.C., Rosenberger, P., Kuhlicke, J., \& Eltzschig, H.K. HIF-1-dependent repression of adenosine kinase attenuates hypoxiainduced vascular leak. Blood $111: 5571-5580$ (2008).

34. Morote-Garcia, J.C., Rosenberger, P., Nivillac, N.M., Coe, I.R., \& Eltzschig, H.K. Hypoxia-inducible factor-dependent repression of equilibrative nucleoside transporter 2 attenuates mucosal inflammation during intestinal hypoxia.Gastroenterology 136:607-618 (2009).

35. Reutershan, J., Vollmer, I., Stark, S., Wagner, R., Ngamsri, K.C., \& Eltzschig, H.K. Adenosine and inflammation: CD39 and CD73 are critical mediators in LPS-induced PMN trafficking into the lungs. FASEB J $23: 473-482$ (2009).

36. Schingnitz, U., Hartmann, K., Macmanus, C.F., Eckle, T., Zug, S., Colgan, S.P., \& Eltzschig, H.K. Signaling through the A2B adenosine receptor dampens endotoxin-induced acute lung injury. J Immunol $184: 5271-5279$ (2010).

37. Synnestvedt, K., Furuta, G.T., Comerford, K.M., Louis, N., Karhausen, J., Eltzschig, H.K., Hansen, K.R., Thompson, L.F., \& S.P. Colgan. Ecto-5'-nucleotidase (CD73) regulation by hypoxia-inducible factor-1 mediates permeability changes in intestinal epithelia. J Clin Invest 110 : 993-1002 (2002)

38. Thompson, L.F., Eltzschig, H.K., Ibla, J.C., C.J. Van De Wiele, Resta, R., J.C. Morote-Garcia, \& S.P. Colgan. Crucial role for ecto-5'nucleotidase (CD73) in vascular leakage during hypoxia. J. Exp. Med. 200 : 1395-1405 (2004).

39. Eckle, T., Grenz, A., Kohler, D., Redel, A., Falk, M., Rolauffs, B., Osswald, H., Kehl, F., \& Eltzschig, H.K. Systematic evaluation of a novel model for cardiac ischemic preconditioning in mice. Am J Physiol Heart Circ Physiol 291 : H2533-2540 (2006).

40. Redel, A., Jazbutyte, V., Smul, T.M., Lange, M., Eckle, T., Eltzschig, H., Roewer, N., \& F. Kehl. Impact of ischemia and reperfusion times on myocardial infarct size in mice in vivo. Exp Biol Med (Maywood) $233: 84-93$ (2008).

41. Warth, A., Eckle, T., Kohler, D., Faigle, M., Zug, S., Klingel, K., Eltzschig, H.K., \& H. Wolburg. Upregulation of the water channel aquaporin-4 as a potential cause of postischemic cell swelling in a murine model of myocardial infarction. Cardiology $107: 402-410$ (2007).

42. Dewald, O., Frangogiannis, N.G., Zoerlein, M.P., Duerr, G.D., Taffet, G., Michael, L.H., Welz, A., \& M.L. Entman. A murine model of ischemic cardiomyopathy induced by repetitive ischemia and reperfusion. Thorac Cardiovasc Surg $52: 305-311$ (2004).

43. Ito, W.D., Schaarschmidt, S., Klask, R., Hansen, S., Schafer, H.J., Mathey, D., \& S. Bhakdi. Infarct size measurement by triphenyltetrazolium chloride staining versus in vivo injection of propidium iodide. J Mol Cell Cardiol $29: 2169-2175$ (1997).

44. Schwanke, U., Konietzka, I., Duschin, A., Li, X., Schulz, R., \& G. Heusch. No ischemic preconditioning in heterozygous connexin43-deficient mice. Am J Physiol Heart Circ Physiol 283 : H1740-1742 (2002).

45. Fisher, S.G., \& Marber, M.S. An in vivo model of ischaemia-reperfusion injury and ischaemic preconditioning in the mouse heart. J Pharmacol Toxicol Methods $48: 161-169$ (2002).

46. Bickler, P.E., Zhan, X., Fahlman, C.S. Isoflurane preconditions hippocampal neurons against oxygen-glucose deprivation: role of intracellular $\mathrm{Ca} 2+$ and mitogen-activated protein kinase signaling. Anesthesiology $103: 532-539$ (2005).

47. Chiari, P., Piriou, V., Hadour, G., Rodriguez, C., Loufouat, J., et al. Preservation of ischemia and isoflurane-induced preconditioning after brain death in rabbit hearts. Am J Physiol Heart Circ Physiol 283 : H1769-1774 (2002).

48. Ebel, D., Mullenheim, J., Sudkamp, H., Bohlen, T., Ferrari, J., et al. Role of tyrosine kinase in desflurane- Induced preconditioning. Anesthesiology $100: 555-561$ (2004).

49. Hanouz, J.L., Yvon, A., Massetti, M., Lepage, O., Babatasi, G., et al. Mechanisms of desflurane-induced preconditioning in isolated human right atria in vitro. Anesthesiology $97: 33-41$ (2002).

50. Kersten, J.R., Schmeling, T.J., Pagel, P.S., Gross, G.J., Warltier, D.C. Isoflurane mimics ischemic preconditioning via activation of K(ATP) channels: reduction of myocardial infarct size with an acute memory phase. Anesthesiology $87: 361-370$ (1997).

51. Mullenheim, J., Ebel, D., Frassdorf, J., Preckel, B., Thamer, V., et al. Isoflurane preconditions myocardium against infarction via release of free radicals. Anesthesiology $96: 934-940$ (2002).

52. Redel, A., Stumpner, J., Tischer-Zeitz, T., Lange, M., Smul, T.M., et al. Comparison of isoflurane-, sevoflurane-, and desflurane-induced preand postconditioning against myocardial infarction in mice in vivo. Exp Biol Med (Maywood) 234 : 1186-1191 (2009).

53. Toller, W.G., Kersten, J.R., Gross, E.R., Pagel, P.S., Warltier, D.C. Isoflurane preconditions myocardium against infarction via activation of inhibitory guanine nucleotide binding proteins. Anesthesiology 92 : 1400-1407 (2000). 
54. Weber, N.C., Toma, O., Awan, S., Frassdorf, J., Preckel, B., et al. Effects of nitrous oxide on the rat heart in vivo: another inhalational anesthetic that preconditions the heart? Anesthesiology $103: 1174-1182$ (2005). 